\title{
Amino acid mineralization by Serratia marcescens
}

\author{
MONIKA GÓRAK*, MAEGORZATA BRZEZIŃSKA-RODAK, \\ MAGDALENA KLIMEK-OCHAB, EWA ŻYMAŃCZYK-DUDA \\ Department of Bioorganic Chemistry, Faculty of Chemistry, Wrocław University of Technology, Wrocław, Poland \\ ${ }^{*}$ Corresponding author: monika.gorak@pwr.wroc.pl
}

\begin{abstract}
The influence of different cultivation conditions (medium, $\mathrm{pH}$ values, temperatures of the process, air access) on the ability of amino acid mineralization via oxidative deamination by Serratia marcescens (facultative anaerobic bacterial strain) was examined. Among 11 tested substrates - amino acids serine and proline, of both optical configurations, were chosen as model substrates for the determination of the acceptable range of the value of external factors influencing the mineralization process. Both $\mathrm{pH}$ and oxygen access were found to be limiting factors. While the acidic $\mathrm{pH}$ switched off the mineralization, restricted aeration significantly reduced the effectiveness of the process, extending the time for its completion.
\end{abstract}

Key words: biotransformation, amino acids, Serratia marcescens

\section{Introduction}

Due to their unique properties (number of enzymatic activities; ability to adapt to various environmental conditions) microorganisms play an important role in many natural processes, as well as in technological processes developed by humans. The individual ability of microorganisms to catalyze various chemical transformations and to overproduce multiple metabolites in quantities far above their own needs have led to their practical and commercial use. Microorganisms have these abilities owing to the possibility to control their metabolism by a rationally designed selection of appropriate cultivation conditions. Among others enzymes, amino acid oxidases are proteins of great importance because of their current and possible applications. These enzymes catalyze oxidative deamination and are thus involved in amino acid metabolism in prokaryotic cells. Therefore, monitoring the effectiveness of amino acid mineralization allowed to determine if the examined bacterial strain can be considered as a source of this particular enzymatic activity (Pilone, 2000; Molla et al., 2003).

Amino acid oxidases belong to ubiquitous enzymes, detected not only in microbial cells, but also in insects, amphibians, reptiles, birds and mammals (Palenik and Morel, 1990; Gabler and Fischer, 1999; Pollegioni et al., 2007; Khoronenkova and Tishkov, 2008). These enzymes constitute a flavin adenine dinucleotide (FAD) that contains oxidoreductases which catalyze the oxidative deamination of amino acids, resulting in the production of corresponding imino acids and hydrogen peroxide (Pollegioni et al., 2008). $\mathrm{FADH}_{2}$ is oxidized spontaneously in the presence of molecular oxygen which, in turn, is reduced to hydrogen peroxide. Then imino acids - products of the deamination step - are hydrolyzed, non-enzymatically, to $\alpha$-keto acids and ammonia (Pilone, 2000).

Living cells can produce flavoenzymes that convert amino acids of $L$-configuration (LAAO, $L$-amino acid oxidase E.C.1.4.3.2) and/or $D$-amino acids (DAAO, $D$-amino acid oxidase E.C.1.4.3.3) into corresponding $\alpha$-keto acids. Some amino acid oxidases are characterized by strict substrate specificity, while others exhibit relatively broad substrate specificity (Geueke and Hummel, 2002). In microorganisms, these enzymes are involved in the catabolic utilization of exogenous amino acids that are tapped for growth, whereas the role of this class of enzymes in mammals is still under debate (Pilone, 2000; Molla et al., 2003).

High stereospecificity of amino acid oxidases toward amino acids provides for their applications in biotechnology and medical diagnostics. They can serve as biosensors to determine the level of appropriate amino acids in biological samples of different origin (Wcisło et al., 2007). Additionally, oxidases serve as convenient tools in biocatalysis. $D$-amino acid oxidase was applied in the synthesis of several chiral sintons - starting compounds 
for the production of chiral medications (Tan et al., 2006). Another area of amino acid oxidase application is represented by the conversion of amino acids into the corresponding $\alpha$-keto acids (Brodelius et al., 1981) and enzymatic production of optically pure amino acids (Trost and Fischer, 2002).

Although amino acid oxidases have been identified in a variety of taxa, in biotechnology, enzymes of eukaryotic origin are the most utilized ones (venom poisons, fungi etc.) (Tan et al., 2006; Tan and Fung, 2008). Thus it is deemed important to find an alternative, inexpensive and convenient method of obtaining amino acid oxidases from other unexplored organisms. There are a wide range of bacterial species which could provide unlimited possibilities of investigating new cost-effective sources of these oxidoreductases, needed for realization of various biotechnological processes.

This paper is probably the first report on the effect of different cultivation conditions such as: media, temperature, $\mathrm{pH}$, agitation rate and substrate structure, on the catabolism of selected amino acids by Serratia marcescens cells. Earlier studies have revealed the involvement of oxidases in the utilization of amino acids by microorganisms either as a nitrogen source without relying on amino acid uptake (Palenik and Morel, 1990) or as a nitrogen and carbon source with transport of substrates into the cell.

Our data supplement rather limited knowledge of the enzyme of prokaryotic origin.

\section{Materials and methods}

\section{Microorganisms}

Serratia marcescens (1608) strain was purchased from the Leibniz Institute DSMZ - the German Collection of Microorganisms and Cell Cultures (Braunschweig, Germany).

\section{Chemicals}

All chemicals and reagents of highest purity available were purchased from Sigma Aldrich (St. Louis, Missouri, United States), POCh (Gliwice, Poland) or BIOCORP (Warszawa, Poland).

\section{Media and cultivation conditions}

The bacterial strain was routinely maintained on nutrient agar slant and stored at $4{ }^{\circ} \mathrm{C}$. S. marcescens was cultivated in 250-ml Erlenmeyer flasks containing $100 \mathrm{ml}$ of Nutrient Broth (NB) or Davis Minimal Broth (DMB).
Liquid NB consisted of $(\mathrm{g} / \mathrm{l})$ : beef extract 0.4 ; enzyme - hydrolyzed casein 5.4; peptone 4.0; yeast extract 1.6; $\mathrm{NaCl}$ 6.0. DMB consisted of (g/l): $\mathrm{K}_{2} \mathrm{HPO}_{4}$ 14.0; $\mathrm{KH}_{2} \mathrm{PO}_{4} 6.0 ;\left(\mathrm{NH}_{4}\right)_{2} \mathrm{SO}_{4} 2.0 ; \mathrm{MgSO}_{4} \cdot 7 \mathrm{H}_{2} \mathrm{O} 0.2 ; \mathrm{C}_{3} \mathrm{H}_{4}(\mathrm{OH})$ $(\mathrm{COONa})_{3} 1.0 ; 20 \%$ glucose solution $-40 \mathrm{ml}$.

The $S$. marcescens cells were cultivated at $120 \mathrm{rpm}$ at $30^{\circ} \mathrm{C}$ for $24 \mathrm{~h}$. Next, bacterial biomass was separated by centrifugation $(3100 \times g, 15 \mathrm{~min})$ and the wet cells were used for biotransformation of amino acids.

\section{Biotransformation - general procedure}

Fresh biomass was transferred to the $30 \mathrm{ml}$ of citrate buffer ( $\mathrm{pH} 4.0 ; 0.1 \mathrm{M})$ or a phosphate buffer ( $\mathrm{pH} 7.0$; $0.017 \mathrm{M}$ or $\mathrm{pH} 9.0 ; 0.06 \mathrm{M}$ ), with an addition of substrate - the final concentration of amino acid was $30 \mathrm{mM}$. The biotransformation was carried out for $76 \mathrm{~h}$, at different temperatures: $20^{\circ} \mathrm{C}$ or $30^{\circ} \mathrm{C}$; with $(120 \mathrm{rpm})$ or without shaking. The procedure was completed by removing the biomass by centrifugation $(3100 \times g, 15 \mathrm{~min})$ and the supernatant was subsequently analyzed. The control experiment was carried out in a bioconversion medium without $S$. marcescens cells, according to abovementioned biotransformation procedure, no reaction was observed.

All experiments were performed in replicates of three times, to confirm the reproducibility of results.

\section{Analytical methods}

The results were evaluated by thin-layer chromatography (TLC) with TLC plastic sheets precoated with Silica Gel 60. Chromatograms were developed using eluent consisting of $n$-butanol, acetic acid and water $(4: 1: 1 ; \mathrm{v} / \mathrm{v})$. Spots were visualized using standard ninhydrin reagent ( $2 \%$ acetone solution).

\section{Results and discussion}

Serratia species, particularly $S$. marcescens, are significant human pathogens and research regarding these bacteria in terms of physiology is still of interest. This study aimed to identify the conditions of amino acid mineralization by $S$. marcescens cells. Among all tested amino acids of both $L$ - and $D$-configurations, enantiomeric forms of serine as well as proline were completely metabolized. Thus a detailed study was conducted using these amino acids. The experimental results were visualized with a simple ninhydrin reaction on the solid TLC phase. The vanishing spots - lack of the amino acids 
in the medium - observed after the bioconversion phase, proved that deamination was completed.

Bacterial strains belonging to Enteriobacteriaceae were shown to utilize amino acids in a variety of ways, including oxidative deamination (Raunio and Jenkins, 1973; Duerre and Chakrabarty, 1975). Several cell-surface and endocellular amino acid oxidases have been reported in fungal and bacterial species (Saleem et al., 2012; El-Sayed et al., 2012). Some of them are characterized by strict substrate specificity, while others exhibit a relatively broad substrate specificity. Microbes with broad substrate-specific oxidases are characterized by extracellular deamination of amino acids (Braun et al., 1992). This eliminates the number of amino acid transporters needed to obtain substrates which then serve as a source of nitrogen. Instead, these kind of microbes mainly use the $\mathrm{NH}_{4}{ }^{+}$transport system, carrying the ammonium ions, liberated from amino acids, across the plasma membrane (Kleiner, 1985). The obtained results suggest that in the case of $S$. marcescens, endocellular oxidases of narrow substrate tolerance do exist, because the utilization of amino acids was limited to proline and serine. The advantage of taking this route is that microorganisms can take up amino acids that not only supply nitrogen but are also a carbon source. In addition, the ability to incorporate amino acids directly into protein saves the energy required for carbon skeleton synthesis. Serratia marcescens is known for the production of a pigment called prodigiosin (PG). A metabolic correlation between amino acid supplementation of Serratia cultivation medium and PG formation has been previously documented (Williamson et al., 2005). Proline acts as a raw material that is incorporated into the pyrrole rings of 4-methoxy-2-2'-bipyrrole-5-carbaldehyde $(\mathrm{MBC})$ to promote pigment production. Amino acids without pyrrole structure (e.g., serine) also play a role in the $\mathrm{MBC}$ production. Most probably, serine is also involved in the synthesis of various precursors of pigments (Williamson et al., 2005).

Our experiments allowed the comparison of the influence of environmental conditions on the amino acid uptake by Serratia cells. The two crucial factors affecting the catabolism of proline and serine in $S$. marcescens cells seemed to be: i) the cultivation medium and ii) the $\mathrm{pH}$ of biotransformation environment (Table 1).

The biocatalyst biomass derived from two different cultivation media: complex $\mathrm{NB}$ and mineral DMB.
Results of the bioconversion show that when the prokaryotic cells were cultivated on DMB, the best rate of utilization was obtained at alkaline $\mathrm{pH}$ for $L$-isomers of both tested amino acids. This effect was observed, in particular, in the case of $L$-proline application. Bioconversion of this compound was completed after $56 \mathrm{~h}$, at $30^{\circ} \mathrm{C}$ as well as at $20^{\circ} \mathrm{C}$, while under the same temperatures and cultivation medium, but at neutral $\mathrm{pH}$, bioconversion of the $L$-proline was observed after 70 and $76 \mathrm{~h}$, respectively. The enzymes present in microbial cells cultivated on $\mathrm{NB}$ were active only at alkaline $\mathrm{pH}$, and $L$-proline biotransformation was completed after $70 \mathrm{~h}$.

Amino acids bioconversion using $\mathrm{DMB}$ as cultivation medium was more effective at alkaline $\mathrm{pH}$, not only for $L$-proline but also for $L$-serine, which was oxidized just after $24 \mathrm{~h}$, at $30^{\circ} \mathrm{C}$, while at the neutral $\mathrm{pH}$, at $30^{\circ} \mathrm{C}$, this compound was bioconverted after $70 \mathrm{~h} . L$-serine was the best inducer of active enzyme also for the biocatalyst cells cultivated on $\mathrm{NB}$, and the reaction was completed after $24 \mathrm{~h}$ at neutral $\mathrm{pH}$.

The studies described above indicate that the $\mathrm{pH}$ tolerance of the enzyme in $S$. marcescens cells strongly depends on the cultivation medium. Thus, at $\mathrm{pH} 7$, the oxidase activity was induced faster for the biomass derived from $\mathrm{NB}$, whereas at $\mathrm{pH} 9$ the best results were obtained for the cells cultivated on DMB in the case of $L$-serine application.

The influence of $\mathrm{pH}$ also varies depending on the structure of the bioconverted amino acids. This can be clearly seen when the proline is used as an enzyme activity inducer. Despite the temperature of the process, enzymatic oxidative deamination of $L$-proline at alkaline $\mathrm{pH}$ was completed within only $56 \mathrm{~h}$ for biomass derived from DMB. Moreover, these conditions also allowed to complete the process for the biocatalyst cells cultivated on the NB medium within $70 \mathrm{~h}$, at both studied temperatures of the process. Contrary to the above, at $\mathrm{pH} 7$ there is a strong correlation between the enzyme activity, the cultivation medium and the reaction temperature since, as observed in Table 1, only the cells of $S$. marcescens derived from DMB medium were able to convert $L$-proline at $30^{\circ} \mathrm{C}$ faster than at $20^{\circ} \mathrm{C} ; 70$ and $76 \mathrm{~h}$, respectively. This suggests that higher $\mathrm{pH}$ values stabilize the native enzyme structure, increasing its temperature tolerance.

The obtained results confirm the previously published literature data and the finding that amino acid oxi- 
Table 1. Comparison of the results of proline and serine oxidative deamination carried out under aerobic conditions

\begin{tabular}{c|c|c|c|c|c|c|c|c}
\hline & \multicolumn{9}{c}{$\mathrm{pH}$ of biotransformation media } \\
\hline & \multicolumn{4}{|c|}{$\mathrm{NB}$} & \multicolumn{4}{c}{$\mathrm{pH} 9.0$} \\
\hline & $30^{\circ} \mathrm{C}$ & $20^{\circ} \mathrm{C}$ & $30^{\circ} \mathrm{C}$ & $20^{\circ} \mathrm{C}$ & $30^{\circ} \mathrm{C}$ & $20^{\circ} \mathrm{C}$ & $30{ }^{\circ} \mathrm{C}$ & $20^{\circ} \mathrm{C}$ \\
\hline$L$-serine & $24 \mathrm{~h}$ & $24 \mathrm{~h}$ & $70 \mathrm{~h}$ & $70 \mathrm{~h}$ & $70 \mathrm{~h}$ & $1 . b$. & $24 \mathrm{~h}$ & $56 \mathrm{~h}$ \\
\hline$D$-serine & $1 . b$. & $1 . b$. & $70 \mathrm{~h}$ & $1 . b$. & $1 . b$. & $1 . b$. & $1 . b$. & $1 . b$. \\
\hline$L$-proline & $1 . b$. & $1 . b$. & $70 \mathrm{~h}$ & $76 \mathrm{~h}$ & $70 \mathrm{~h}$ & $70 \mathrm{~h}$ & $56 \mathrm{~h}$ & $56 \mathrm{~h}$ \\
\hline$D$-proline & $70 \mathrm{~h}$ & $1 . b$. & $1 . b$. & $1 . b$. & $1 . b$. & $1 . b$. & $1 . b$. & $1 . b$. \\
\hline
\end{tabular}

$24 \mathrm{~h}, 32 \mathrm{~h}, 48 \mathrm{~h}, 56 \mathrm{~h}, 70 \mathrm{~h}, 76 \mathrm{~h}$ - the approximate time after the completion of biotransformation; l.b. - lack of bioconversion - unreacted substrate remained in the biotransformation medium

Table 2. Comparison of the optimal conditions of bioconversion of $L$-serine and $L$-proline

\begin{tabular}{l|c|c|c}
\hline \multicolumn{1}{c|}{ Amino acid } & $L$-serine & $L$-serine & $L$-proline \\
\hline Condition & $\mathrm{NB}$ & $\mathrm{DMB} / \mathrm{NB}$ & $\mathrm{DMB}$ \\
\hline Oxygen access & unlimited & limited & unlimited \\
\hline $\mathrm{pH}$ of bioconversion & 7.0 & 9.0 & 9.0 \\
\hline Temperature & $20^{\circ} \mathrm{C}, 30^{\circ} \mathrm{C}$ & $20^{\circ} \mathrm{C}, 30^{\circ} \mathrm{C}$ & $20^{\circ} \mathrm{C}, 30^{\circ} \mathrm{C}$ \\
\hline
\end{tabular}

dation depends on the ionization state of the substrate. Amino acids with a deprotonated amino group are more suitable oxidase substrates than their positively charged forms. Therefore, it seems to be reasonable that the maximum activity of amino acid oxidase should be observed at alkaline $\mathrm{pH}$, providing the uncharged amino group (Harris et al., 2001; Tishkov and Khoronenkova, 2005).

In contrast to alkaline $\mathrm{pH}$, the application of acidic $\mathrm{pH}$ inhibited the amino acid oxidase activity. At a low $\mathrm{pH}$, the enzyme was inactivated and the variation in selected external factors did not reduce the negative effect of acidic $\mathrm{pH}$ on the enzymatic activity (data not shown). $\mathrm{pH} 4.0$ strongly affected the process, since the bacterial flavoenzymes (from various sources) are stable at the range of $\mathrm{pH}$ 6.0-9.0 (Geueke et al., 2007; Pollegioni et al., 2008). The examined strain - S. marcescens - showed narrow tolerance to potentially lethal levels of acidity (pH 2.0-3.5) (Nojoumi et al., 1995).

The agitation rate which affects the mass transfer of both oxygen gas and medium components into the growth media was also a crucial factor for the bioconversion of amino acid by $S$. marcescens. The limited oxygen access (required for cofactor - FAD regeneration - reoxidation) significantly influenced the effectiveness of the process. Such conditions were implied in the inactivation of the enzyme when $L$-proline was used as enzyme synthesis stimulator. On the other hand, S. marcescens was able to bioconvert $L$-serine even under stationery conditions, under limiting oxygen. In this case, the biotransformation process was completed after $24 \mathrm{~h}$, at alkaline $\mathrm{pH}$, at both studied temperatures $\left(20^{\circ} \mathrm{C}, 30^{\circ} \mathrm{C}\right)$, as well as for the biomass derived from NB and DMB. The results obtained at $\mathrm{pH}$ 7.0, for the same inducer, were comparable to those obtained under aerated conditions, at a similar temperature and $\mathrm{pH}$ range (Table 1 ).

The studies described above suggest that the application of stationery conditions and alkaline $\mathrm{pH}$ values of the biotransformation medium indicate a unique activity of oxidase which is able to operate under limited oxygen access (Table 2). A possible explanation of this phenomenon is that $S$. marcescens as a facultative anaerobic organism can grow without oxygen and is capable of using another compound as the final electron acceptor.

It is also clearly seen (Table 1) that there is a correlation between the temperatures of the process and the $\mathrm{pH}$ of the reaction medium. Thus, for $L$-serine at $\mathrm{pH}$ 7.0 , there is no difference in the enzyme activity, independently of other variable factors, while at $\mathrm{pH} 9.0$, the 
enzymatic activity at $20^{\circ} \mathrm{C}$ markedly decreases. In contrast, when $L$-proline was applied, at pH 9.0, the enzymatic activity remained at the same level for both temperatures but at $\mathrm{pH}$ 7.0, the lower temperature was associated with the lower oxidase activity. It is noteworthy that for $D$-isomers of the inducers, in every case, no reaction was observed at $20^{\circ} \mathrm{C}$. Moreover, amino acid oxidases with $D$-isomer preference are more sensitive to variable reaction conditions. In the present study, the preferable $\mathrm{pH}$ was 7.0 and $30^{\circ} \mathrm{C}$ while at $\mathrm{pH} 9.0$ no reaction was reported.

If the biomass of $S$. marcescens cells derived from $\mathrm{DMB}, D$-serine was converted within $70 \mathrm{~h}$, whereas if the biocatalyst cells derived from the NB, oxidation of $D$-proline was completed after $70 \mathrm{~h}$. These results also suggest that such conditions stabilize the structure of the enzyme. Additionally, the experiments described above indicate that amino acid oxidase from $S$. marcescens exhibits minimal activity toward $D$-amino acids, compared to the results obtained for $L$-amino acids, under the same biotransformation conditions.

It appears that $S$. marcescens does not synthesize different types of amino acid oxidases as a consequence of variable cultivation conditions. It is possible that the cells produce only one enzyme, which is active toward tested amino acids. Particular enzymes are synthesized only when the specific substrate is present in the medium. Amino acid oxidase synthesis was induced by the presence of $D$ - or $L$-isomers of endogenous amino acids - serine and proline, in the biotransformation medium, under specific conditions. Thus, it is possible that amino acid oxidase from $S$. marcescens can be an inducible enzyme, similar to some amino acid oxidases obtained from other bacteria (Raunio and Jenkins, 1973) or yeast (Pilone et al., 1989).

The activity of amino acid oxidase in $S$. marcescens cells that we investigated can be applied not only for the conversion of natural amino acids but also structural analogues of these compounds. Additionally, atypical enzymatic activity induced by $L$-serine under stationery conditions can be employed in biotechnological applications, leading to chiral intermediates - natural amino acid analogues.

This work expands and enhances the knowledge regarding the activity of amino acid oxidases of prokaryotic origin and their sensitivity to external factors influencing the cultivation process. The experiments discussed here allow the elaboration of optimal procedures, which may prove useful for further studies.

\section{Acknowledgements}

This work was financed from a project "Biotransformation for pharmaceutical and cosmetics industry" No. POIG.01.03.0100-158/09-06, and partly by European Union funds within the European Regional Development Fund for the Innovative Economy.

\section{References}

Braun M., Kim J.-M., Schmid R.D. (1992) Purification and some properties of an extracellular L-amino acid oxidase from Cellulomonas cellulans AM8 isolated from soil. Appl. Microbiol. Biotechnol. 37: 594-598.

Brodelius P., Nilsson K., Mosbach K. (1981) Production of $\alpha$-keto acids Part I. Immobilized cells of Trigonopsis variabilis containing D-amino acid oxidase. Appl. Biochem. Biotechnol. 6: 293-308.

Duerre J.A., Chakrabarty S. (1975) L-amino acid oxidases of Proteus rettgeri. J. Bacteriol. 121: 656-663.

El-Sayed A.S., Shindia A.A., Zaher Y. (2012) L-amino acid oxidase from filamentous fungi: screening and optimization. Ann. Microbiol. 62: 773-784.

Gabler M., Fischer L. (1999) Production of a new D-amino acid oxidase from the fungus Fusarium oxysporum. Appl. Environ. Microbiol. 65: 3750-3753.

Geueke B., Weckbecker A., Hummel W. (2007) Overproduction and characterization of a recombinant $D$-amino acid oxidase from Arthrobacter protophormiae. Appl. Microbiol. Biotechnol. 74: 1240-1247.

Geueke B., Hummel W. (2002) A new bacterial L-amino acid oxidase with a broad substrate specificity: purification and characterization. Enzyme. Microb. Technol. 31: 77-87.

Harris C.M., Pollegioni L., Ghisla S. (2001) pH and kinetic isotope effects in D-amino acid oxidase catalysis. Evidence for a concerted mechanism in substrate dehydrogenation via hydride transfer. Eur. J. Biochem. 268: 5504-5520.

Khoronenkova S.V., Tishkov V.I. (2008) D-amino acid oxidase: physiological role and applications. Biochemistry (Moscow) 73: 1511-1518.

Kleiner D. (1985) Bacterial ammonium transport. FEMS Microbiol. Lett. 32: 87-100.

Molla G., Motteran L., Piubelli L., Pilone M.S., Pollegioni L. (2003) Regulation of D-amino acid oxidase expression in the yeast Rhodotorula gracilis. Yeast 20: 1061-1069.

Nojoumi S.A., Smith D.G., Rowbury R.J. (1995) Tolerance to acid in pH 5.0-grown organisms of potentially pathogenic Gram-negative bacteria. Lett. Appl. Microbiol. 21: 359363.

Palenik B., Morel F.M.M. (1990) Amino acid utilization by marine phytoplankton: a novel mechanism. Limnol. Oceanogr. 35: 260-269.

Pilone M.S. (2000) D-amino acid oxidase: new findings. Cell Mol. Life Sci. 57: 1732-1747. 
Pilone M.S., Verga R., Fretta A., Hanozet G.M. (1989) Induction of D-amino acid oxidase by D-alanine in Rhodotorula gracilis grown in defined medium. J. Gen. Microbiol. 135: 593-600.

Pollegioni L., Molla G., Sachi S., Rosini E., Vega R., Pilone M.S. (2008) Properties and application of microbial D-amino acid oxidases: current state and perspective. Appl. Microbiol. Biotechnol. 78: 1-16.

Pollegioni L., Piubelli L., Sacchi S., Pilone M.S., Molla G. (2007) Physiological functions of D-amino acid oxidases: from yeast to humans. Cell Mol. Life Sci. 64: 1373-1394.

Raunio R.P., Jenkins W.T. (1973) D-alanine oxidase from Escherichia coli: localization and induction by L-alanine. J. Bacteriol. 115: 560-566.

Saleem A., Moharram A.M., Fathy N. (2012) Production and optimization of D-amino acid oxidase which is involved in the biosynthesis of $\beta$-lactam antibiotics. Afr. J. Microbiol. 6: 4365-4376.

Tan N.-H., Fung S.-Y. (2008) Snake venom L-amino acid oxidases and their potential biomedical applications. Malaysian J. Biochem. Mol. Biol. 16: 1-10.
Tan Q., Sog Q., Wei D. (2006) Single-pot conversion of cephalosporin $C$ to 7-aminocephalosporanic acid using cellbound and support-bound enzymes. Enzyme Microb. Technol. 39: 1166-1172.

Tishkov V.I., Khoronenkova S.V. (2005) D-amino acid oxidase: structure, catalytic mechanism and practical application. Biochemistry (Moscow) 70: 40-51.

Trost E.M., Fischer L. (2002) Minimization of by-product formation during $D$-amino acid oxidase catalyzed racemate resolution of D/L-amino acids. J. Mol. Catal. B Enzym 19-20: 189-195.

Wcisło M., Compagnone D., Trojanowicz M. (2007) Enantioselective screen - printed amperometric biosensor for the detection of D-amino acids. Bioelectrochem 71: 91-98.

Williamson N.R., Simonsen H.T., Ahmed R.A.A., Goldet G., Slater H., Woodley L., Leeper F.J., Salmond G.P.C. (2005) Biosynthesis of the red antibiotic, prodigiosin, in Serratia: identification of a novel 2-methyl-3-n-amylpyrrole (MAP) assembly pathway, definition of the terminal condensing enzyme, and implications for undecylprodigiosin biosynthesis in Streptomyces. Mol. Microbiol. 56: 971-989. 